\title{
The Study on the Change of Consumers' Brand Recognition
}

\author{
Liang Chen \\ East China University of Science and Technology \\ School of Business \\ Shanghai, China \\ sanlychen@126.com \\ Minyue $\mathrm{Hu}$ \\ East China University of Science and Technology \\ School of Business \\ Shanghai, China \\ yue_atsh@163.com
}

\author{
Xiaobei Li \\ East China University of Science and Technology \\ School of Business \\ Shanghai, China \\ xiaobeili@ecust.edu.cn
}

\begin{abstract}
Consumers' low-end recognition on Chinese brands largely hinders the leap from low-end to high-end. This study focuses on the change process and conditions of consumers' brand recognition and the article is a partial result. The grounded-theory is applied to analyze the affecting factors and the conditions in which original recognition changes, and ultimately the process model of recognition change is obtained. The model indicates that there are three cognitive states during the formation of the recognition, namely ignorance, acceptance and belief. According to the development of these three states, the paper also draws the affecting factors. To explore the recognition change process from a psychological perspective helps to master the consumers' brand recognition changing process in a real business environment.
\end{abstract}

Keywords- Self-owned Brand; Brand Recognition; Change of Recognition; Affecting Factors; Process Model

\section{INTRODUCTION}

In recent 30 years, with the rapid development of China's economy, Chinese enterprises have grown up. However, almost all successful brands have one thing in common, that is, seizing market share as quickly as possible by low-cost advantage. Maybe it is a holy grail when brands enter the market initially, but in the process of development of the brand, this "low-level" impression will be gradually implanted into consumers' attitudes, and it is difficult to change. Consumer cognition of low-end on Chinese brands largely hindered the leap from low-end to high-end.

In March 2009, Chery launched "multi-brand strategy", expanding the single-brand Chery to four brands which are Karry, Chery, Riich and Rely, and the latter two are highend brands. Originally, Chery hoped to enhance the brand image through multi-brand strategy to gain high profits. However, due to the positioning of consumers that Chery is a cheap means of transport, it is difficult to be compared to other high-end car brands. The rejection of consumers led to the failure of Chery's transformation. In the early
August 2012, Chery announced to divest Rely and Karry, and return to single brand, which is to say Chery's multibrand strategy was failed.

Most Chinese brands face the same challenges as Chery that how to develop from low-end to high-end, such as Lenovo, Geely, Li Ning, Changhong, TCL, Coolpad, Meizu, Gree, Midea, Galanz and so on. These companies do not go smoothly, and even unsuccessfully. This is because China's own brand has long been known as the "low-level". Once consumers have a brand awareness, it is hard for them to change the recognition in a short time. Therefore, if Chinese brands want to enter the high-end market, the first thing to do is to change consumers' brand recognition.

Then, when China's own brand enterprises continuously improve product performance and quality, how should they change consumers' brand recognition in order to achieve the leap from low to high?

Currently, most studies on brand awareness analyzed how the recognition affected consumer buying behavior, such as Zhuang Ailing and Yu Weiping (2010), Yang Weiwen and Liu Xin (2010), Hu Liwen (2010). Jiang Xionglian and Zhu Huihuang (2010) discussed the mechanism of brand awareness and brand effect. To sum up, few studies have analyzed the process and conditions of changing consumers' brand awareness. However, the analysis of the process and conditions of changing consumers' brand awareness plays a very important role in changing consumers' brand recognition to achieve the leap from low to high.

Accordingly, this study emphasizes the process and conditions of changing consumers' brand recognition, and the paper is the first phase of this research. It mainly explores the changing process of human's cognition, i.e. when will the orig inal cognition change? What will make the cognition change? 


\section{RESEARCH DESIGN}

Due to the complexity and difficulty in studying the changing process of consumer awareness, the study adopted a strategy of reducing difficulty. To make substantial progress, this study analyzed the changing process of college students' cognition, understood the process from a psychological perspective, and then laid a solid foundation for grasping the cognitive process of consumers in a real business environment.

\section{A. Research Object}

In order to understand the changing process and conditions of students' cognition, we have done an experiment. During the class, students were required to read at least one of the twelve books that written by three authors (each author has four books). The three authors are Nan Huaijin, Brian L. Weiss and Frederick William Engdahl, and their repres entative works are "The Analects Interpretation", "Past and Present", "A Century of War". Master Nan introduces Chinese Sinology, Brian L. Weiss introduces a variety of cure cases using past recall therapy from a psychological perspective, and Frederick William Engdahl analyzes world events from a geopolitical perspective. After reading, students were asked to write reading notes with at least 2,000 words. The reading note should be divided into three parts, which are brief introduction of the content, changes in cognition, and changes in behavior. Finally, we identified the students who had great changes in cognition and behavior, and we conducted in-depth interviews with the m to understand the process that how they changed their cognitions and behaviors.

\section{B. Research Method}

This article aims to explore the changing process of cognition, and dig out the factors that have influence on original cognition. So it is an exploratory research. In order to have an in-depth exchange with the objects, we carry out data collection through interviews. Interview is a method to collect information through face-to-face talk with the research objects. It is flexible and adaptable to be applied to the individualized research, which can meet the research's need. Therefore, this paper will use interview as the main research method, and supplemented by the secondary data collection to expand the entire survey.

In addition, we use grounded theory during the data analysis phase. It is a way that applies a series of methods systematically to summarize the theory in a specific area. Grounded theory emphasizes on data abstraction by encoding, constant comparis on and saturation analys is, and ultimately summarizes theories or hypothesis. Compared with other methods, grounded theory has the advantage of establishing assumption and developing theory, and it will contribute to original discovery.

This paper attempts to explore the changing process of cognition, and come to the factors that affect the original recognition, which belongs to exploratory study, so it uses grounded theory for further data processing.

\section{Data Collection}

1) The choice of the interview sample

In December 2012, the 160 reading notes were distinguished, from which we selected 22 students who had significant changes in cognition and behavior as our interview objects. The significant change mentioned here is concluded from the reading notes. But whether it is as true as stated in reading notes, we need to do further validation through interviews. Due to the schedule, we ultimately obtained 19 copies of the interview data (See Table 1).

TABLE I. INTERVIEW SAMPLE

\begin{tabular}{|l|c|}
\hline \multicolumn{1}{|c|}{ Selected Book } & Number \\
\hline Brian L. Weiss "Past and Present"/"Circle of Life” & 10 \\
\hline Nan Huaijin "Talking about Hist ory and Life" & 3 \\
\hline Nan Huaijin "TheExperience of History" & 3 \\
\hline Nan Huaijin "Readings of Chuang-Tzu” & 1 \\
\hline Frederick William Engdahl "A Century of War" & 1 \\
\hline Frederick William Engdahl "Seeds of Destruction” & 1 \\
\hline
\end{tabular}

\section{2) The collection of the interview data}

In the first data collection (December 11th, 2012), we interviewed six students whose selected books related to three different authors.

In the second data collection (January 17th, 2013), according to the first data encoding and the analys is results by constant comparison, we made some addition to interviews. At this stage, 10 students were interviewed.

In the third data collection (March 18th, 2013), in order to further test the obtained coding results, we intervie wed another three students.

In these three data collection process, each interviewee was interviewed about 20-40 minutes. In order to avoid the deviation of understanding, we gave information feedback to the interviewees during the process. Meanwhile, we recorded the interviews to ensure the integrity and accuracy of information gathering.

\section{Data Analysis}

Firstly, we dealt the first collected 3 interviews with open coding, and got event codes. Then we compared the event codes, and discussed the same part in which we got the different event codes, until we reached a consensus. Similarly, in the subsequent coding process, we encoded the same data independently, and then compared the result, and discussed the different encoding until we reached a consensus.

Secondly, we continued to do substantive coding on the event codes with open mind, to acquire the substantive concept. Then we compared the concept with other concept and event constantly, until the concept reached saturation, that is, there will be no longer any new concept to generate.

Thirdly, we analyzed the association between the concepts through constant comparison, to summarize the theoretical category and its characteristics. On this basis, we concluded the core category and its characteristics.

Next, we conducted a second data collection, and did selective coding on the second data under the guidance of core category. Then we constantly compared the results of coding with category and core category, and added the newly generated category to the existing category. The 
comparison process has been continued until the category and core category reached saturation, that is, there will be no longer any new category or core category to generate. The core categories obtained in this paper are three cognitive states (See Table 2). In addition, the paper also excavated the influencing factors during the formation of cognition (See Table 3).

Finally, we carried out a third data collection, still did selective coding under the guidance of core category, and did saturation analysis on category and core category. The third collected data didn't generate new category and core category, and thus they reached saturation. So the process of data collection an analysis ended.

TABLE II. CORE CATEGORY AND ITS CHARACTERISTICS

\begin{tabular}{|c|c|c|}
\hline No & $\begin{array}{c}\text { Core } \\
\text { Category } \\
\text { (Cognitive } \\
\text { State) } \\
\end{array}$ & Characteristics \\
\hline 1 & Ignorance & $\begin{array}{l}\text { A lack of comprehensive or profound } \\
\text { understanding of a concept, in which state, } \\
\text { others' negative or positive view will affect the } \\
\text { judgment and the judgment of the authorities } \\
\text { or the stagers tends to become theircognition }\end{array}$ \\
\hline 2 & Acceptance & $\begin{array}{l}\text { When exposed to the new concept and it is } \\
\text { difficult to verify that the new concept is true } \\
\text { in a short time, at least not falsifiable, people } \\
\text { seem to have a conflict between new concept } \\
\text { and current cognition, but in essence, it is } \\
\text { reasonable. } \\
\text { After an in-depth understanding of the new } \\
\text { concept, people blend it into their own system, } \\
\text { and then the cognitive consistency appears. } \\
\text { When old and new ideas are coordinated, the } \\
\text { parties will further understand the new ideas by } \\
\text { analogy, and then reflect on their own. At this } \\
\text { time, the cognition has changed, but this } \\
\text { change will not last a long time. }\end{array}$ \\
\hline 3 & Belief & $\begin{array}{l}\text { Personal verification is repeated several times; } \\
\text { the new ideas are constantly being confirmed } \\
\text { and being effectively applied to real life; } \\
\text { behaviors change and last for a long time; new } \\
\text { cognition generates. }\end{array}$ \\
\hline
\end{tabular}

TABLE III. THE INFLUENCING FACTORS IN THE FORMATION OF COGNITION

\begin{tabular}{|c|c|c|}
\hline Stage & Influencing Factor & Concept \\
\hline \multirow{2}{*}{ Ignorance } & Interest / Curiosity & $\begin{array}{l}\text { When having no } \\
\text { underst anding of the concept, } \\
\text { people reach it through } \\
\text { interest or curiosity. }\end{array}$ \\
\hline & $\begin{array}{l}\text { Authority's } \\
\text { Recommendation }\end{array}$ & $\begin{array}{l}\text { In the state of ignorance, the } \\
\text { judgment of the authorities or } \\
\text { the stagers tends to become } \\
\text { people's cognition. }\end{array}$ \\
\hline \multirow{2}{*}{$\begin{array}{l}\text { Ignorance } \\
\rightarrow \\
\text { Acceptance }\end{array}$} & $\begin{array}{l}\text { Positive Stimulation } \\
\text { from People Around }\end{array}$ & $\begin{array}{l}\text { When exposed to new } \\
\text { concept, positive stimulation } \\
\text { from people around will help } \\
\text { them to further understand it. }\end{array}$ \\
\hline & $\begin{array}{l}\text { The Way to } \\
\text { Falsification }\end{array}$ & $\begin{array}{l}\text { If the concept can't be } \\
\text { proved false, people will try } \\
\text { to accept it. }\end{array}$ \\
\hline \multirow{2}{*}{$\begin{array}{l}\text { Acceptance } \\
\rightarrow \text { Belief }\end{array}$} & Practical Application & $\begin{array}{l}\text { If the concept is confirmed } \\
\text { through personal verification, } \\
\text { people will gradually enter } \\
\text { the state of belief. }\end{array}$ \\
\hline & $\begin{array}{l}\text { Repetition and } \\
\text { Solidification }\end{array}$ & $\begin{array}{l}\text { After several-time } \\
\text { verification, the memory is } \\
\text { solidified and new cognition } \\
\text { generates. }\end{array}$ \\
\hline
\end{tabular}

\section{RESEARCH RESULT}

According to grounded theory, this study concluded three cognitive states in the formation of cognition, which are ignorance, acceptance and belief (See Fig. 1). The detailed description of each state is as follows .

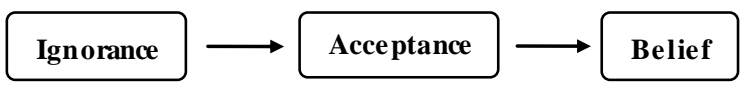

Figure 1. Three Cognitive States

\section{A. The State of Ignorance}

Ignorance refers to a lack of comprehensive or profound understanding of a concept, in which state, others' negative or positive view will affect the judgment and the judgment of the authorities or the stagers tends to become their cognition. As in the interviews, a student said, "Orig inally, I did not believe in reincarnation, and I have never known such a concept." "I know the exist of Islam, but I do not know what it is." In other words, the student didn't have a good understanding of reincarnation or Is lam and both of them were just a concept to him. In the absence of a comprehensive and profound understanding, the student has already got a judgment that reincarnation is a superstition, and I cannot believe it.

In this state, there are two ways that will affect whether the parties reach the new concept, which are interest or curiosity and authority's recommendation.

Interest or curiosity means when the parties don't understand a concept, they will reach the concept due to interest or curiosity. In the interviews, we found that there were many students chose "Past and Present" written by Brian L. Weiss. When asked the reason, a great deal of them said they were interested in or curious about the book. 
Thus, interest and curiosity is an important cause of concern raised.

Authority's recommendation is a second way to new concept when the parties have no understanding of the concept, especially when holding a negative perception. In other words, the reason why people pay attention to the concept is authority's recommendation. For example, many students read these books seriously because of the teacher's recommendation.

\section{B. The Change from the State of Ignorance to Acceptance}

When exposed to the new concept, many people will compare it to the old ideas, and reach a conclusion that the notion is wrong or directly give up the notion, and then the process of cognition will end. So, how can we make this part of people willing to further understand new concepts, and then guide them to accept this concept? Here, the positive stimulation from people around plays a critical role. In the interviews, we found that many students considered reincarnation to be incredible when they read "Past and Present" initially. But after discussion with people around and learn other people's personal experiences, their ideas will change, so will their attitudes to reincarnation.

To further test the credibility of the new concept, the parties may take a variety of ways to verify the authenticity, such as continuing to read the author's book, communicating with friends around, comparing the content with their own experiences, etc. When new ideas cannot be falsified, people are gradually stepping into the acceptance state. However, the state of acceptance is a progressive layer from shallow to deep: 1) The stage in which old and new ideas conflict but reasonable. When exposed to the new concept and it is difficult to verify that the new concept is true in a short time, at least not falsifiable, people seem to have a conflict between new concept and current cognition, but in essence, it is reasonable. 2) Cognitive consistency stage. After an in-depth understanding of the new concept, people blend it into their own system, and then the cognitive consistency appears. 3) Behavior adoption stage. When old and new ideas are coordinated, the parties will further understand the new ideas by analogy, and then reflect on their own. At this time, the cognition has changed, but this change will not last a long time.

\section{The Change from the State of Acceptance to Belief}

At the state of acceptance, the behavioral changes may not last a long time. So, if we want to make persistent behavior changes, we should apply new ideas in practice. That is to say, if the new ideas can be interpreted into current things, and be constantly confirmed in the practice process or bring positive effects to them, people will change the cognitive attitudes to the new concept from acceptance to belief, and their behaviors will also change. In the interview, a student often calms the mind in his spare time after reading "Talking about History and Life" written by Master Nan. When asked why he made such a change, he said that he was affected by the thoughts in the book. Before reading, he was always busy but really didn't know what he was doing, but now he tried to understand the "calm" talked by Master Nan, and then he felt much better in mentality. Therefore, when people try to apply new ideas into real life and make some achievement, they will really start to believe the new ideas and their behaviors will also change.

If we want to make the change in behavior last much longer, or comp letely abandon the original perception, then the process of personal inspection needs to be repeated several times. Only when new ideas are constantly being confirmed and being effectively applied to real life, can people's memories be solidified. At this time, new cognition generates.

\section{The Model of Cognition Formation}

Combined with the affecting factors, we can summarize the process of cognitive change (See Fig. 2). When people are in the ignorance state, in which the parties have no understanding of the concept, others' negative or positive view, especially the authorities' or the experts' will affect the judgment. Due to interest, curiosity or authority's recommendation, people are more likely to reach the new concept. When exposed to the new concept, many people will compare it to the old ideas, and reach a conclusion that the notion is wrong or directly give up the notion. At this time, if there is no positive stimu lation from people around, the process of cognition will end. On the contrary, the parties tend to verify the authenticity of the new ideas through other ways. When new ideas cannot be falsified, people are gradually stepping into the acceptance state.

The state of acceptance is a progressive layer from shallow to deep: 1) The stage in which old and new ideas conflict but reasonable. When exposed to the new concept and it is difficult to verify that the new concept is true in a short time, at least not falsifiable, people seem to have a conflict between new concept and current cognition, but in essence, it is reasonable. 2) Cognitive consistency stage. After an in-depth understanding of the new concept, people blend it into their own system, and then the cognitive consistency appears. 3) Behavior adoption stage. When old and new ideas are coordinated, the parties will further understand the new ideas by analogy, and then reflect on their own. At this time, the cognition has changed, but this change will not last a long time.

On the basis of accepting new ideas, if the parties try to interpret current things with the new concept, and it is confirmed, the memory will be solidified. At this time, new cognition generates and the behaviors change. The parties step into the third cognitive state: belief.

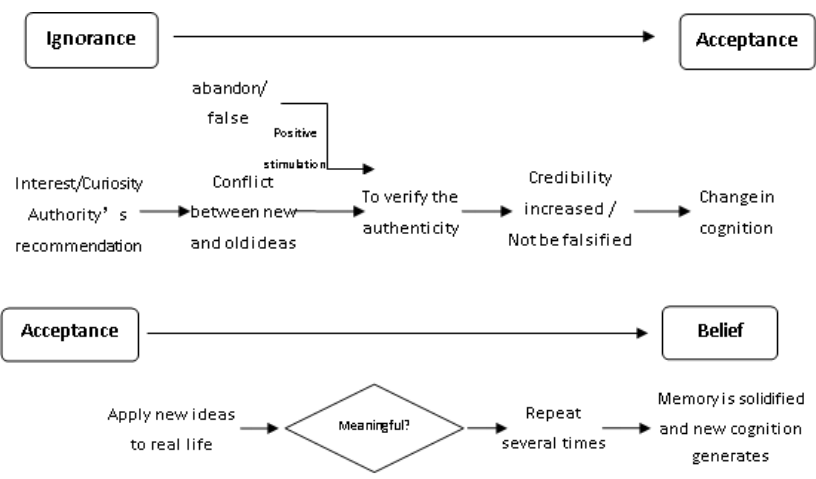

Figure 2. The Model of Cognitive Change 


\section{E. To Understand the Failure of Chery Using the Model}

In 2009, Chery announced a multi-brand strategy. After launching the high-end brand - Rely, the first high-end brand model - Rely G5 was officially announced in Beijing. The vehicle ranges from 14 million to 18 million, and considers the Mazda 6 and the new Buick Regal as "imaginary enemy". In order to attract consumers' attention to the high-end brand image, Chery spent a lot of money organizing the challenge in Nürburgring and the Rely G5 was endorsed by Lionel Messi, which was consistent with the view that consumers' attention can be attracted through interest or curiosity.

At this point, many consumers generated conflict between Chery's old and new brand, and then some consumers who have strong curiosity (early adopters) tried to use Rely G5. But in the process of using, people found that the actual performance of the car had a big gap between the really high-end automobile brands. So people came to a conclusion that Chery was still a relatively lowend brand, and chose to give up the judgment Rely was a high-end brand. Because of these negative judgments of early adopters, people who in the ignorance state further strengthen the cognition that Chery is a low-end brand, and most consumers don't consider that Rely is a high-end brand. Finally, Rely G5 didn't perform well in the market, which determined the failure of Chery's multi-brand strategy.

\section{CONCLUSIONS}

This paper summarizes the model of cognitive change. The model indicates that there are three cognitive states during the formation of the cognition, namely ignorance, acceptance and belief. According to the development of these three states, the paper also draws the affecting factors In the state of ignorance, influencing factors include interest, curiosity and authority's recommendation. In the changing process from ignorance to acceptance, the positive stimulation from people around and the way to falsification take effect. In the changing process from acceptance to belief, the key factor is the personal verification which is repeated severaltimes.

This paper is the first phase of the research on how to change the Chinese customers' perception of the lower quality of domestic brands. It solves the changing process and conditions of cognition. In later study, we will analyze the changing process and conditions of consumers' lowerquality recognition on domestic brands in real environ ment.

\section{REFERENCES}

[1] Hu L W. Brand recognition and selection: Based on the perspective of rural communities[J]. Jiangxi Social Sciences, 2010, (3): 228231.

[2] Jiang L X, Zhu H H. Brand recognition mode and brand effect mechanism: The theory construction beyond "Cognition-Property" paradigm[J]. Management World, 2010, (9): 95-115.

[3] Baker D F, Baker S J. To "catch the sparkling glow": A canvas for creativity in the management classroom[J]. Academy of Management Learning \& Education, 2012, 11(4): 704-721.

[4] Yang W W, Liu X. The effect of brand recogniton on consumer purchase behavior[J]. Business Research, 2010, (3): 158-162.

[5] Ye D. Brand construction: From Chery's strategy of "ret urning to a single brand"[J]. Advertising (Comprehensive), 2012, (10): 47-48.

[6] Zhuang A L, Yu W P. The effect of brand recognition on consumer purchase decision under the perspective of Information Processing[J]. Intelligence Magazine, 2010, (7): 203-207.

[7] Glaser, B. G., Strauss, A. L. The discovery of grounded theory: strategies for qualitative research[M]. New York: Aldine Publishing Company, 1967.

[8] Glaser, B.G. Basics of Grounded Theory analysis: emergence vs. Forcing[M]. Mill Valley: Sociology Press, 1992,.

[9] Glaser, B.G. Theoretical sensitivity: Advances in the methodology of Grounded Theory[M]. Mill Valley: Sociology Press, 1978.

[10] Barkema H G, Chen X P, et al. West meets East: New concepts and theories[J]. Academy of Management Journal, 2015. 58 (2): 460-479. 